REPORT

\title{
Organizing the Work of the Research Library
}

August 18, 2016

Roger C. Schonfeld

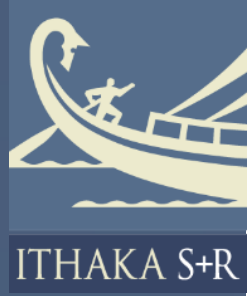




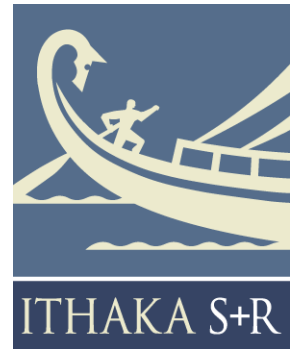

Ithaka $\mathrm{S}+\mathrm{R}$ is a strategic consulting and research service provided by ITHAKA, a not-for-profit organization dedicated to helping the academic community use digital technologies to preserve the scholarly record and to advance research and teaching in sustainable ways. Ithaka $\mathrm{S}+\mathrm{R}$ focuses on the transformation of scholarship and teaching in an online environment, with the goal of identifying the critical issues facing our community and acting as a catalyst for change. JSTOR, a research and learning platform, and Portico, a digital preservation service, are also part of ITHAKA.
Copyright 2016 ITHAKA. This work is licensed under a Creative Commons Attribution-NonCommercial 4.0 International License. To view a copy of the license, please see http://creativecommons.org/licenses/by-nc/4.0/.

ITHAKA is interested in disseminating this brief as widely as possible. Please contact us with any questions about using the report: research@ithaka.org. 


\section{Introduction and Executive Summary}

Established in an era when the collection was truly at the heart of the library, and when building and maintaining it was the focus of its work, the research library is today moving away from organizational structures centered around building and supporting the general collection. Research libraries are undertaking a number of radical transformations: from print towards electronic, from local towards shared, from licensed towards open, from general towards distinctive, from collections towards engagement, from selector towards partner. To support this transformation, libraries are evolving structures designed to embrace the library's full potential as a central campus partner supporting the use, and sometimes creation, of information resources for research, teaching, and learning.

\section{Research libraries are undertaking a number of radical transformations: from print towards electronic, from local towards shared, from licensed towards open, from general towards distinctive, from collections towards engagement, from selector towards partner.}

In this project, Ithaka $\mathrm{S}+\mathrm{R}$ examined the organizational structure of research libraries as well as related leadership and change management issues through a series of interviews with selected library directors. When discussing organizational structure, it is clear that, while some directors are students of this topic, far more interpret it through the lens of their own particular leadership experience. Some focus on professional development or on organizational culture, others focus on strategic planning or on getting things done. While this paper is focused on the structural components of library leadership, it recognizes that in organizational practice these issues are all interconnected, and in leadership styles structure is sometimes a byproduct rather than an organizing principle.

When research libraries were more collections-centric operations, they tended to have more process-driven, departmentally focused structures. In recent years, many libraries have shifted their emphasis towards keeping up to date with, or leading changes in, research, teaching, and learning practices, while also addressing university strategic imperatives. As a result, directors are gravitating towards structures that allow innovation, that can stretch to incorporate new services, and that align with a new 
information environment and the changing place of the research university in society. Because organizational structures establish teams, build accountability, and create incentives, they are vital.

This issue of organizational structure is especially prescient at this time when more than half of ARL directors have been appointed since 2010, and the pace of leadership change is expected to continue for some time. With leadership change often comes organizational change. New directors, frequently appointed with an explicit charge to make change, have been experimenting with new structures while also seeking to learn from the experiments of colleagues. This piece examines the state of academic library organizational structures in late 2015 and some of the emerging trends.

Ultimately, this project analyzed a diversity of models and identified the major commonalities across institutions, as well as some of the intentional differences. Key findings include:

- Library directors appear to be shifting how they structure the role of associate university librarians (AULs), moving away from seeing them principally as division leads and towards seeing them more fully as organizational leaders.

- Directors are using organizational structure to drive a reallocation of the staffing and materials budgets for general collections, with a long-term objective of reducing both in favor of other priorities. The alignment between strategy and organizational structures in these areas of responsibility are especially well established.

- Directors are also pressing for new approaches to outreach and engagement roles, an area with a great deal of experimentation.

- Finally, directors are least uniform in the areas of library technology, where approaches range from efforts to build Silicon Valley-style product organizations to those where directors seem uncertain how best to manage technology resources strategically.

Today, there appears to be no single optimal model for a research library's organizational structure. The different approaches being pursued reflect efforts to experiment and innovate in the context of different views on leadership, different organizational histories and cultures, and a variety of other factors. The snapshot provided in this report suggests broad considerations for other libraries pursuing organizational change. 


\section{Project Scope and Approach}

This project was conducted based on interviews with currently sitting and recently retired academic library directors. It did not incorporate the perspectives of others in the organization.

Participation is intentionally focused on larger institutions, where organizational size and complexity adds an important dimension to the research questions under study. Interviewees were selected intentionally to oversample those institutions and leaders believed to have been innovating, in one way or another, with organizational structure. The project is therefore not intended to be representative of research libraries broadly but to explore some of the changes and experiments being undertaken with respect to organizational structure.

Interviews were largely conducted by telephone, although it was possible to meet one director face to face. The basic interview guide is included as Appendix A, but in several cases subjects chose to emphasize adjacent subjects and interviews were allowed to proceed according to the subjects' inclinations. All interviews were conducted in the second half of 2015 .

Interviewees are shown along with their then-current or former director/dean positions:

- Martha Bedard, University of Connecticut, previously University of New Mexico

- Jon Cawthorne, West Virginia University

- Carol Diedrichs, Ohio State University, previously University of Kentucky

- Charles Eckman, University of Miami, previously Simon Fraser University

- Geneva Henry, George Washington University

- Lorraine Haricombe, University of Texas Austin, previously University of Kansas

- Wendy Lougee, University of Minnesota

- Rick Luce, University of Oklahoma, previously Emory University, Los Alamos National Laboratory

- Brian Lym, Adelphi University

- James Neal, retired from Columbia University, previously Johns Hopkins University and Indiana University

- Sarah Pritchard, Northwestern University, previously University of California Santa Barbara and Smith College 
- MacKenzie Smith, University of California Davis

- Carla Stoffle, retired from University of Arizona

- Gary Strong, retired from University of California Los Angeles, previously Queens Library

- Ed van Gemert, University of Wisconsin, Madison

- $\quad$ Kay Wall, retired from Clemson University, previously University of Southern Mississippi

- Karen Williams, University of Arizona

- $\quad$ Lizabeth (Betsy) Wilson, University of Washington

Interviewees were promised that their remarks would not be used for attribution. To help preserve anonymity, this report omits gendered pronouns and uses the pronouns "they," "them," and "their" as the generic singular, and it uses the term "director" generically regardless of the title of the library chief executive. As a result of the promised anonymity, most participants spoke with great candor about their approaches to leadership, decision-making, and organizational structure.

In preparation for the interview themselves, information about the organizational structure of the library, as presented on the library website, was gathered. Many interviewees shared internal information in advance of the interview about the organization or about a recent reorganization.

In the analysis of the interviews and these other materials, several common structural elements and themes emerged. Those are used to organize this report.

Although this project was initially intended to focus only on organizational structure, library directors think carefully about how to accomplish their missions, and it was impossible to limit them to questions about organizational structure. The reader will therefore find in this report, to some degree, a description of prevailing library leadership philosophies.

Since this report is a summary narrative, not a scientific analysis, there are no statistics or percentages. When the report describes what directors believe, it is simply reporting on the views of a majority of interviewees. The report presents the broad perspectives of nearly 20 library leaders who are working in a time of profound change. 


\section{Acknowledgments}

I am grateful to EBSCO for its sponsorship that made this study possible and for Scott Bernier, its vice president for marketing, who saw the importance of undertaking this project. I thank Amy Buckland, Ken Burhanna, Dennis Clark, Brian Keith, Kimberly Lutz, Deanna Marcum, Tim McGeary, James Neal, Barbara Rockenbach, Hannah Sommers, Claire Dougherty Stewart, and Carla Stoffle for helpful comments on the working draft.

\section{High Level Structure}

The libraries reviewed in this project included a number of different types of organizational structures, and directors also described structures they inherited or attempted, but have since abandoned. Five essential types of structures were identified.

Unit Heads: This model is generally found at comparatively smaller libraries, in which each unit head reports directly to the director, who can have eight or more reports. Sometimes there is a single assistant/associate director, whose role is generally to manage administrative functions such as budget, human resources, and so forth.

Place-based: In a large campus library system with many locations and service points, the reporting structure is organized around directors of each of the libraries, with public and technical services, among others, decentralized in each library location. This model has been largely retired in recent decades, and many departmental and branch libraries have been closed or consolidated, or technical and administrative functions centralized, but elements of this structure can still be found in some library organizations.

AUL: All units and staff report administratively and professionally up through a group of associate university librarians. There are generally three to four AULs, although at larger and more complex research libraries there may be more such leaders. Sometimes there is an AUL for administrative functions such as HR, development, and finance while in other cases the functions all report directly to the director.

Deputy: Most if not all library operations report to a single deputy director, who takes responsibility for the day to day work of the library. The director focuses on "outward" or "future" issues, such as university relations, development work, or strategic projects.

Team-based: Teams are created to work more closely together and with one another, often on a somewhat self-organizing basis more so than a hierarchically managed basis. 
Probably no library falls squarely into one of these reporting structures. Instead, library directors frequently borrow from multiple models to suit the needs of their organization.

\section{The Director}

Most of the directors who participated in this project have the title of dean or vice or associate provost. As a dean, or sometimes with a title such as university librarian, one serves as a peer of the academic deans, who are the chiefs of the university's schools and colleges. In some cases, such as in larger universities with many schools, this may be a disadvantage, as the deans may operate fairly autonomously and may have little direct access to the provost. In those cases, depending on the provost in question, the title of vice or associate provost, may come with greater access to the provost's office and more regular opportunities for direct access with this senior university leader. Occasionally, the vice provost title is awarded in recognition of additional responsibilities that the director has taken on, beyond leading the library, and it is often a gateway to some university responsibilities such a chairing searches for deans. When these responsibilities do not fit into the provost's office, the title can instead be vice president.

There have been a number of cases in recent years where library directors are "dual hatted" with other major leadership roles or titles. In addition to their dean or director titles, Betsy Wilson of Washington also serves as vice provost for digital initiatives, ${ }^{1}$ James Hilton of Michigan also serves as vice provost for digital education and innovation, ${ }^{2}$ Rick Luce of Oklahoma also serves as associate vice president for research, ${ }^{3}$ and Jeff MacKie-Mason of Berkeley also serves as chief digital scholarship officer. ${ }^{4}$ In some cases these titles represent areas of responsibility that are absent from most directors' portfolios; in other cases, these titles may help to signal that the library is taking on an area of responsibility that, while perhaps not widely recognized at the institution, may be common elsewhere. A small number of directors, such as Rebecca Graham of Guelph, 5 also serve as CIO, but the organizational structures associated with merged library and IT divisions were not considered in this project.

\footnotetext{
${ }^{1}$ See http://www.lib.washington.edu/dean/leadership/cabinet/betsyw.

${ }^{2}$ See http://www.lib.umich.edu/users/hilton.

${ }^{3}$ See https://vpr-norman.ou.edu/users/rick-luce.

${ }^{4}$ See http://evcp.berkeley.edu/news/announcement-appointment-university-librarian.

${ }^{5}$ See http://www.uoguelph.ca/news/2012/03/new cio named.html.
} 
Like employees everywhere, directors are invested in their relationship with their supervisor. The supervisor is almost always the provost, although one director reported having negotiated a dual reporting relationship that allowed for occasional access to the university president. Directors keenly recognized that they serve at the pleasure of this individual and that when there is a change in provost there can be a real risk to their own employment, especially if there is discontent in their own ranks or on campus with the services provided by the library.

\section{"If the director isn't clear about what they want to do, it makes it a challenge to get anything done."}

In discussing their role, some directors conceptualize themselves in leadership terms. Some focus on establishing a vision for the library and leading change in that direction. One was clear in articulating, "If the director isn't clear about what they want to do, it makes it a challenge to get anything done." In this view, the director needs to understand their own individual vision well enough to be able to communicate it clearly.

Several directors who had only a small number of predecessors over the past several decades reflected on the perception that this had yielded relatively static organizations. In those cases, they felt an imperative to drive change in some combination of culture, services, and strategy.

Others focused somewhat less on overall leadership and somewhat more on specific aspects of their responsibility. These directors emphasized the work that is the director's alone, including such responsibilities as development, capital projects, and strategic initiatives. Sometimes these directors characterized their role as more external than those of others in the library, especially in the case of development.

Many directors spoke about the influences on their own growth as organizational leaders and their thinking on organizational structure and related issues. Directors who had previously served in this role at other libraries were more likely to express their confidence. On the other hand, those who were newer directors were more likely to look for learning opportunities. In some cases, they were mindful in seeking other university library directors as peer mentors, participating in leadership programs, or retaining an executive coach.

When speaking about their role, many interviewees could not avoid speaking about the significance of trust: mutual trust with their supervisors, trust in (and among) their 
leadership team, and trust in their colleagues in working with other campus units. When trust is present in all three of these areas, directors seem to act with confidence and to empower their organization far more so than when it is partially or entirely absent.

Some directors reflected at length about the phases of their leadership. Being able to determine whether one can take on an externally-oriented development role from the start, or whether there is internal rebuilding to address first, was not easy for all directors to see in advance, even those in a second directorship. One director reflected ruefully on the need to have enough presence with staff at the beginning to gain the trust to take on these more external responsibilities.

Some directors understood the campus culture, university leadership expectations, and library idiosyncrasies clearly before assuming their new roles. Others described just how difficult it was to do so and the surprises they found upon assuming the directorship. In several cases, they reflected with regret that they could not, or did not, better understand cultural dynamics and governance complexities more fully prior ahead of time. It was not clear whether they would have elected not to accept the position as a result, or simply would have used that information in negotiating the offer or in other ways to improve their ability to be successful.

\section{A Leadership Team}

Library directors spoke at length about the need to build a strong leadership team. Many interviewees reported that in one way or another this is the issue that been the greatest challenge in thinking about organizational design.

\section{Directors wish to have a leadership team that is focused on the needs of the library as a whole.}

Directors wish to have a leadership team that is focused on the needs of the library as a whole, and in many cases beyond the library to the university. They feel that, all too often, managers focus too narrowly on advocating for the needs of their units and divisions. They wish for, and have tried to create, a leadership team that can translate the library's strategic direction into the library's operations. There was a sense that the senior managers are not "administration," if they ever were, but "leadership," with one interviewee emphasizing the need to clarify continuously this nomenclature. 
The ability to select one's leadership team was a major factor for many directors. Some reported with gratitude that their predecessors had held open numerous leadership positions, making it possible for them to build the structure they wanted with individuals they had selected ("a true gift"). In other cases, members of the senior leadership team departed within a year or two of their arrival, providing some continuity but nevertheless affording the new director the opportunity to make structural changes with less heartache. Other directors found ways to organize at the highest levels around the capabilities of the leaders they inherited or otherwise work around the inflexibility they faced in being unable to develop their own senior leadership team. It was unusual but not impossible for a director to remove someone from an AUL-level position.

Directors have had varying levels of control and influence in filling open senior leadership positions. Building a pool of strong candidates can be easier if the director has and makes use of a strong professional network, if the library is located in a geographical location seen as comparatively desirable, and if the leadership position is defined in a way that is broadly appealing. In selecting the leadership team, most directors try to take an active role in the process. Depending on the organization, some are able to chair a search committee, while others choose a final candidate from among a small number recommended by a search committee. ${ }^{6}$ These latter processes were reported in several cases to have been problematic for directors, especially those relatively new to a leadership role, who felt unable to push back against the established process. It was striking to hear of leadership teams whose creation was influenced more strongly by other factors than by the director's own objectives.

\section{AUL Roles}

Many directors have intentionally crafted the positions of their direct reports, and their leadership structure, with the objective of change. In some cases, this has meant shifting from a larger group of unit heads reporting to the director to a smaller group of AULs constituting a leadership team. In other cases, this has meant reducing the management burdens on some, if not all, of their direct reports to ensure that these individuals afford time and attention to strategy and leadership issues. Ultimately, there appeared to be a clear trend towards building a team that was more focused on organizational leadership and less on staff management.

Even so, there was a real split among the interviewees in terms of their views about the qualifications of AULs. Some were looking primarily for individuals with hands-on

\footnotetext{
${ }^{6}$ Deanna Marcum, "Talent Management for Academic Libraries," Ithaka S+R Issue Briefs, September 1, 2015, http://dx.doi.org/10.18665/sr.241937.
} 
experience and expertise in particular areas of responsibility. Others were seeking to build teams of strong visionaries and leaders who could readily assume one another's responsibilities or a library director role at any moment. Some of the latter group were very anxious to communicate how eager they are for their AULs to develop professionally and to take on director roles as soon as possible.

Most directors viewed their AULs as the core of their leadership team. Directors tended to bring this group (also including directors for development, communications, and/or human resources / talent management) together on a regular basis in some kind of administrative leadership team or cabinet meeting. Some directors have eliminated these meetings or reduced their frequency in favor of encouraging the AULs to meet together to resolve issues themselves and occasionally bring proposals to the director for approval. On the other hand, depending on the culture and the nature of the team, at least one director has felt threatened by AULs working together and seemingly against them. ${ }^{7}$

Several directors spoke about the need to elevate the leadership of the library to be more strategic and responsive to campus issues. In some cases, having built a strong cabinet, library directors reported an acute awareness that their AULs have not managed their own divisions with nearly enough strategic focus. Instead, they saw their AULs getting bogged down in minutiae with their teams. In these cases, directors were unsure how to empower their smart, strong cabinet members to serve as effective leaders of their divisions. In general, they described efforts to help their AULs learn how to let go of the details and focus on the big picture.

\section{Unit Heads and Middle Managers}

A recurring theme in the interviews with directors is the challenge of balancing the need for strong unit leadership with the broader need to lead the library as a whole. This issue has been at the forefront in the restructuring of several libraries included in this study.

Several directors felt that middle managers and unit heads are the key obstacles towards widespread organizational change. Directors believe that these individuals try to protect their own turf (perhaps in some cases because they do not feel secure in their roles) rather than working cooperatively on behalf of the library broadly. As a result, several directors have sought ways to strengthen management skills and organizational perspective at middle management levels.

\footnotetext{
${ }^{7}$ One reader raised the question as to whether tenured AULs are more likely to challenge sitting directors but that issue did not arise in the interviews.
} 
Looking at some of these issues, both at the library leadership level and the division leadership levels, several directors reflected on the challenge of effectively measuring performance. There was a sense that unit heads and middle managers, and even more so frontline staff, are not evaluated against measures that are consistent with the strategic leadership roles that directors were hoping would cascade through the organization.

Some directors set up a variety of mechanisms to allow them to personally reach deeper into the organization. One director established quarterly meetings with their indirect reports, one example of the variety of more inclusive leadership structures they sought to develop. Several directors emphasized how important it is not only that they fund professional development activities but that they proactively identify and even create meaningful professional development for their middle managers and frontline colleagues.

Several directors are taking a very different approach, attempting to dis-establish the notion of purely hierarchical management. While libraries have a long tradition of work through committees and working groups, in these cases the directors are looking to incorporate team-based operations into the organizational structure rather than as a shadow structure. They are frustrated with committee-based approaches to priorities such as assessment, looking not just for a coordinator for this type of role but a new mechanism for managing a strategic priority of this sort. ${ }^{8}$ The specifics of these approaches varied tremendously across the several libraries that are utilizing them, but the common thread appeared to be a strong desire to empower employees throughout the organization by fostering decision-making models at a working level, so that fewer decisions had to be delayed by flowing up the hierarchy and back down again. These team approaches also appear to be linked to directors' efforts to lighten the management burden of AULs and position them more strategically.

\section{Deputy University Librarian}

Several directors spoke about the role of a deputy university librarian, in some cases because they had experienced this role earlier in their career, in other cases because they had eliminated the role upon assuming a leadership position, and in still other cases because they had created such a position.

There appear to be three types of deputy positions:

- Where the majority of library operations report up to this individual.

${ }^{8}$ Gavia Libraria (the Library Loon), "The C-word," December 15, 2011, http://gavialib.com/2011/12/the-c-word/. 
- Where the position serves as first among equals of the AUL's.

- Where someone holding another title implicitly serves as the first among equals of the director's reports.

Directors who felt they themselves were taking on an unusual strategic project were most likely to establish a deputy position. One example was a director taking on the development, design, and construction work required to completely renovate the main campus library. Another was a director determined to develop a fundamentally online "21st Century" library. In these circumstances, some directors focus more than others on how to eventually link up the additional "strategic" activity with the other parts of the library operations that are managed by the deputy. There can in some cases be a risk that these two can diverge and can cause tension.

The models here are by no means identical to one another. One director compared the deputy role to a corporate $\mathrm{COO}$, who allows the $\mathrm{CEO}$ to focus on larger strategic and governance issues. Another interviewee used the example of a chief of staff, who funnels only the largest decisions to the director.

Such models seem to succeed when an unusual degree of trust and "chemistry" exists between director and deputy. Consequently, when the director departs their position, and if the deputy does not then assume the director role, a new director is unlikely to develop the same chemistry with the deputy. As a result, these models can be problematic for transitions. Put more bluntly, the deputy should probably assume that when the director leaves they will either assume the directorship or depart themselves. This was the single clearest exception to the notion that leadership teams can in some cases be inherited with success.

\section{Leaders throughout the organization}

Several directors spoke passionately about the need to encourage innovation broadly throughout the organization. They were emphatic that innovation should be possible regardless of one's position in a hierarchy, which was not always seen as possible. One director created an innovation fund, to encourage ideas that might "bubble up" from anywhere to make their way directly to library leaders; this was reported to have helped at least temporarily to break things open. Even though a discussion about leadership throughout the organization was not on the list of interview questions, several directors focused extensively in their interviews on issues of organizational development in this regard. Directors emphasized again and again a desire to empower "frontline" staff who ultimately have better ability to make their own decisions about how best to get their work accomplished to the extent that they are able to see the broader picture of the library's strategic emphasis. 


\section{Several directors spoke passionately about the need to encourage innovation broadly throughout the organization. They were emphatic that innovation should be possible regardless of one's position in a hierarchy.}

Especially at larger libraries, directors indicated that staff collaboration well beyond hierarchical management becomes increasingly important. Many directors referred to a proliferation of teams, cross-functional working groups, and other efforts to break out from a purely functional organization structure. In several cases, directors offered examples illustrating that there was close to "one team for every employee" to show that a good idea had proliferated beyond reason. Some directors have reduced, or expressed an interest in reducing, the number of these groups and the resources they consume. In other cases, there is an effort to ground these structures more directly in the organizational structure, for example by connecting certain types of initiatives with an AUL sponsor, with the view that this can add agility.

Several of the interviewees also reflected on factors related to faculty status and/or unions. Faculty status is seen as a challenge in certain circumstances, but even when tenure and promotion was controlled by a committee structure, rather than the dean, directors found creative ways to assert influence. Some directors were accepting of the reality of faculty status and tried to build structures that provided more flat organization or more participatory decision-making. Other directors felt that faculty status undermined their ability to innovate in the ways that their provosts were mandating, and as a result were sidelining librarians with faculty status in a variety of creative ways. In still other cases, sometimes the library dean has tenure and promotion responsibilities for all librarians on campus, even those in other libraries such as law and medicine not formally under their purview, providing substantial influence well beyond the organizational charts. There were also cases where faculty status models and/or union dynamics were seen as more severely diluting the authority of the director and library leadership team.

\section{Organizing to Address the Most Pressing Issues}

Directors discussed their efforts to reshape their organizations to support strategic priorities in three fundamental areas. 


\section{Rethinking collections}

Libraries once distinguished between bibliographer or selector roles, which were responsible for building collections in a field-specific area of expertise, and reference roles, which were responsible for providing user research assistance. Many libraries had parallel hierarchies, one responsible for collections and another for public services. A third hierarchy for technical services completed the three-legged stool. Support and administrative services might be housed in the director's office or might constitute the stool's fourth leg.

In many cases, these hierarchies shifted when the selection and reference roles merged across many institutions in the 1990s. Typically, one AUL retained responsibility for the staff in these roles, while another retained responsibility for the library materials budget. As electronic resource licensing grew in significance in the 1990s, dedicated staff for these purposes were often added in the latter group.

Research libraries almost always organize the collections function under the responsibility of a senior executive officer and member of the director's cabinet, such as an associate university librarian. Sometimes this individual is responsible for other functions as well. In universities with a strong open access mandate, scholarly communications functions are often organized under this leader, supporting a vision that all collections, whether generated internally or acquired elsewhere, are equally important. 9 This clarity of vision may be complicated by the collaborations needed to support various types of digital collections but in theory it is intended to assign responsibility for all collections to a senior leader. Also, in some cases, this leader takes responsibility for certain components of the library's materials processing and descriptive operations, such as acquisitions, cataloging, and/or preservation, which ultimately serve in support of collections.

It is also common for the AUL for collections to focus exclusively on collecting and licensing. In the latter case, the collections executive often has a very small staff, with principal responsibility not for staff management but rather for the materials budget. This model can have its limits, especially if it impedes coordination for the full lifecycle of collections and content access decision-making, but there are also examples of it working well.

\footnotetext{
${ }^{9}$ Deanna Marcum and Roger C. Schonfeld, Office of Scholarly Communication: Scope, Organizational Placement, and Planning in Ten Research Libraries (New York: Ithaka S+R, 2015), http://dx.doi.org/10.18665/sr.275206.
} 
Many of the libraries represented in this project have extensive collaborations around collections, including consortial licensing of digital collections, efforts to share in the management of print collections, preservation initiatives, and more. Staff to support these efforts are sometimes located in consortia or university systems offices, which in at least one case is housed administratively inside the library itself. But while collections executives and staff are frequently involved in collaborations, the interviews with directors produced little indication that there was any direct impact on how the collections organization was structured or the executive role organized.

For several of the interviewees, rethinking the way that collections are organized and staffed represents one of their most significant strategic objectives. Library leaders expressed a desire to address two fundamental issues.

First, at those libraries with an existing investment in special collections, there is great interest, as Rick Anderson has articulated, to "shift our focus from the collection of what we might call "commodity" documents (especially in physical formats) to another activity in which we have also been engaging for many centuries: the gathering and curating of rare and unique documents, including primary source materials." 10 To do so, library directors see the need to shift materials budgets from the acquisition of general collections to the purchase of distinctive collections, increasing the support for these activities through growing or repurposed curatorial, descriptive, and other capacities.

Second, as Anne Kenney has described, many research libraries are looking for ways to move their liaison programs systematically towards new ways of engaging and supporting research and learning. ${ }^{11}$ One reason this is possible is that for many parts of the general collection, less selection is taking place at a title level and much more is taking place through various types of aggregations, collections profiles, and demanddriven models. Another is that directors perceive reference questions through the staffed reference desk model to have declined substantially. As a result, they are looking to transition these staff towards the increasing provision of new services to user populations under an increasingly engaged outreach model.

Fundamentally, many library leaders are grappling with how to build a structure that enables them to accomplish both of these objectives simultaneously.

\footnotetext{
${ }^{10}$ Rick Anderson, "Can't Buy Us Love: The Declining Importance of Library Books and the Rising Importance of Special Collections," Ithaka S+R Issue Briefs, August 1, 2013, http://dx.doi.org/10.18665/sr.24613.

${ }^{11}$ Anne Kenney, "Leveraging the Liaison Model: From Defining 21st Century Research Libraries to Implementing 21st Century Research Universities," Ithaka S+R Issue Briefs, March 25, 2014, http://dx.doi.org/10.18665/sr.24807.
} 
Some libraries have decided to merge all collections responsibilities under one AUL structure. Perhaps counterintuitively, these libraries are emphasizing their strategic desire to shift spending patterns away from general and towards special collections. They empower a single senior individual to administer all the associated budgets, an individual who in turn is assigned a performance objective to shift resource expenditures (such as materials budget and processing operations) from general to distinctive collections. This groups the general and special collections together under one leader whose objective-and budgetary authority-is aligned with the library's strategy.

Other libraries are making a different choice. They are pulling together all the distinctive collections, such as rare books, archives, area studies, and other special collections, into a single AUL structure. This has the effect of putting all the staff who will continue to focus on item-level selection and curation, and their collections, into a single hierarchy, thereby providing greater high-level support and engagement for their work. Perhaps of greater interest, however, is that this makes possible the more fundamental rethinking of selection and associated staffing for general collections. Another AUL is therefore charged with precisely this task, which to a very significant degree can be termed "reimagining the liaison model" (see below under "reimagining outreach").

Most directors are interested in accomplishing both these objectives, of repurposing the budgets and the selectors for general collections. One model emphasizes the materials budget, the other emphasizes staffing roles, but it would be too simple to conclude that the models are selected purely based on the strategy that the library is pursuing. While the directors seemed to organize their high-level structures to give greater priority to one or the other, they are also shifting around responsibilities for technical services, liaisons, and the general collections budget, in an effort to accomplish both objectives together.

\section{Reimagining outreach}

Many of the leaders interviewed for this project were passionate about strengthening the libraries' relationships with faculty members and students and the services they provide in support of research, teaching, and learning. Many see the liaison program (whatever it may be called) at the heart of these efforts. ${ }^{12}$ Several directors emphasized the importance of having the entire library organization-not just liaisons-focused outwardly. The efforts to achieve this vision of stronger relationships and greater engagement are grouped together here under the term "outreach."

\footnotetext{
${ }^{12}$ An important initiative taking place in parallel with this research is reported in Barbara Rockenbach, Judy Ruttenberg, Kornelia Tancheva, and Rita Vine, Association of Research Libraries/Columbia University/Cornell University/University of Toronto Pilot Library Liaison Institute: Final Report (Washington DC: Association of Research Libraries, 2015), at http://www.arl.org/storage/documents/publications/library-liaison-institute-final-report-dec2015.pdf.
} 
While many directors discussed making all librarians responsible for outreach, structurally most of the libraries in the sample are split between roles that can be interpreted as outreach versus those that are "back of the house." Several directors indicated that the greatest share of professional librarians employed by the library were in outreach roles. This seems in some cases to be an intentional shift, a sense of how the work of professional librarians is evolving as compared with that of other library professionals; while in other cases directors were simply describing the reality as they inherited it.

Several interviewees expressed a variety of concerns with the ways that outreach functions are delegated. Many liaison structures charge individual librarians with having a relationship with a given academic department or a small group of departments. Extensive thinking has gone into these models and how best to support them. ${ }^{13}$ But there is evidence that, while these models may have strengths in other areas, they may be providing uneven research support in at least some fields. ${ }^{14}$ Some interviewees also shared the sense that liaisons, especially in a faculty status context, have in some cases encouraged campus dissent from the directions that the library, or at least its leadership, will have chosen to pursue, using the relationships they are charged to build with faculty members in one sense "against" the library. For example, libraries taking new approaches to collections management may find humanities liaisons alerting humanists of the risks to their collections and at least implicitly encouraging objections. Many libraries are trying to strengthen the research support they can provide, and as a result are looking towards different models for its provision, as alternatives or supplements to the subject-organized liaison model.

One important form of outreach has historically been the physical embedding of librarians in the same buildings as many academic departments. While physical library spaces in themselves fall outside the scope of the current project, space considerations are relevant here because many larger research libraries were built as a federation of school and departmental libraries, each with its own director and organizational structure. As spaces are consolidated, so too is staffing. Several interviewees have presided over the reduction in the number of library locations, by closing branch or departmental libraries. These changes are especially common in the sciences, where the digitization of the journal literature reduced substantially the rationale for a collection of print resources in proximity with a scientific laboratory (and in many cases reduced the

\footnotetext{
${ }^{13}$ See for example, Richard Moniz, Jo Henry, and Joe Eshleman, Fundamentals for the Academic Liaison (Chicago: NealSchuman, 2014).

${ }^{14} \mathrm{~A}$ colleague and I found that historians, for example, felt they received a range of types of support from subject specialists, meeting some but not all needs. See pages 20-23 in Jennifer Rutner and Roger C. Schonfeld, Supporting the Changing Research Practices of Historians (New York: Ithaka S+R, 2012), http://dx.doi.org/10.18665/sr.22532.
} 
argument for keeping those materials in print altogether). The process of closing these departmental libraries is far along at many, but not all, institutions included in this project.

One broad direction has been the creation of "hub" libraries for the sciences (or social sciences), containing a variety of resources, staff, and services. These consolidate departmental libraries and increasingly de-emphasize print collections if they contain any substantial amount of them at all. With the shift away from fully developed (if small) departmental libraries towards hubs designed to serve certain macrodisciplinary fields like the sciences, the organizational structure has shifted to some degree as well. Some libraries are using this consolidation as an opportunity to expand services even while reducing (if not eliminating altogether) the tangible collections they provide. For example, Columbia has established digital centers for the humanities, social sciences, and sciences, respectively, each of which is intended to provide expertise for grant seeking, assessment, marketing, support of teaching \& learning, and other priorities. Others are considering building teams of librarians each of which is collectively responsible for a cluster of disciplines-for example, arts or physical sciences. This would have the benefit of colleagues providing one another with mutual support and also redundant staffing. One director mentioned that it would also provide a form of peer support and accountability that can be absent in some traditional liaison models. While some libraries have established AUL-level roles to serve these macrodisciplinary fields, managers for these "hubs" will more typically report to an AUL for services; sometimes both models are used on the same campus for different libraries, for example an AUL for health sciences and a department head for social sciences.

Several directors in this project sample have been implementing, or considering carefully how to build, a different structure and staffing model for campus outreach. The University of Kansas, for example, has entirely reorganized its service provision around user groups such as undergraduate students, graduate students, and faculty members. In other less comprehensive cases, subject-based liaison models are mixed with other mechanisms for delivering services. UCLA integrated specialized services, such as digital humanities support, within its liaison structure..$^{15}$ In other cases, the responsibility of liaisons is being focused more precisely, so that they are recast as "consultants" responsible for in-depth research assistance rather than the many roles they are more generally asked to take on.

\footnotetext{
${ }^{15}$ Marta Brunner's remarks at a symposium in 2013 provide a good illustration of the thinking at UCLA at the time, https://youtu.be/n4XIzp3ExMA?t=3m6s.
} 
Ultimately, many directors spoke of their goal to create opportunities for service development. While this can have structural components, it also had substantial staffing and cultural requirements as well.

\section{Redesigning technology}

Library technology directorates may be the area of libraries where organizations are most different from institution to institution. At some, there is a relatively narrow focus on the building and maintaining of systems, but many have grown into large organizations that play a role in managing a variety of public services as well.

Interviewees indicated a variety of levels of engagement with library technology. Many found that library systems and IT constitute a major area of organizational focus for them, indicating that key strategic priorities including open access, data management, and digital collections, require the participation and leadership of the library technology division. All could speak in concrete terms about specific technology projects or initiatives, such as the selection of an integrated library system. Some had clearly taken ownership of the technology work of the library broadly and expressed varying models for the roles they saw the technology directorate playing under their leadership. Interviewees sometimes reported that they plan to address this area incrementally in the coming years. In still other cases, they seemed to see a technology division as something of a "black box" in terms of their ability to understand its work richly enough to provide leadership and oversight. Directors have a broader range of ability or interest to engage with library technology than they do with collections or outreach.

Few research universities have merged their library with campus IT under a single executive leader. Brandeis, Colorado State, and Guelph are among the few exceptions. None of the interviewees were from such merged organizations. This section therefore only addresses cases where library technology functions are organized substantially within the library.

Interviewees reported a variety of different perspectives on the organizational positioning of library technology. Some directors feel extremely strongly that the library needs to "own" its IT functions (even in the face of some university efforts to reduce costs through centralization in university $\mathrm{IT}^{16}$ ) because that gives its leaders the ability to provide sufficient resources and prioritize the work appropriately. On the other hand, one director bemoaned the clashes associated with bringing "people who do not share

\footnotetext{
${ }^{16}$ See for example: https://stage.cni.org/topics/assessment/changing-for-excellence-libraries-and-it-experience-withcampus-consultants/.
} 
the culture and values" who nevertheless wish to drive decision-making in the library; wondering as a result if the library would be better served by "buying" services from campus IT with a strong service-level agreement. These remarks about organizational positioning were focused on the technical contributions of library technology rather than the public services roles that some technology directorates are taking on.

Many libraries have put all "technology" functions under an AUL for library technology or library IT. This can include functions such as desktop support for staff and public workstations, programming, integrated library systems management, and library website design and management.

In some cases, the purview of this technology directorate has grown to include a variety of other services as well. These can include scanning and other digital library "production” work, user experience, scholarly communications including institutional and other digital repository programs, support for digital humanities, and more. This "omnibus" model houses many of the key strategic initiatives of the library over the past decade. It can require leadership for functions as diverse as engineering, helpdesk, product management, and research support. Perhaps in some cases, this "omnibus" model is as much about a director having identified a strong AUL seen as having an appetite for risk who can serve as portfolio manager for a variety of "innovative" services than it is about technology alone.

\section{While some directors are satisfied that the "omnibus" model for library technology has worked effectively, others have come to question it.}

While some directors are satisfied that the "omnibus" model for library technology has worked effectively, others have come to question it. Perhaps in some cases, it has lost organizational coherence or strategic focus. Some libraries have substantially reorganized their technology offices or likely will do so. One option is to move desktop support to a directorate that also provides finance, HR and organizational development, and similar services, seeing all of them as essentially internal services roles. Many other functions have both a pure technology development/management aspect to them as well as a programmatic aspect. Some libraries have introduced the concept of "business owners" outside the technology directorate to lead certain initiatives, which has become somewhat common for institutional repositories being led programmatically by a scholarly communications office. These efforts can better focus the technology 
directorate on system acquisition, management, development, and maintenance. Widespread efforts have been made to improve collaboration between the technology directorate and other parts of the library for topics from digital collections to the library website itself.

In several cases, however, libraries are pursuing a more radical reconfiguration of technology towards an orientation as more of a "product" organization. This concept of a product organization is modeled on the transformation of Silicon Valley companies away from building computing appliances and systems and towards creating consumer products that are driven by technology. ${ }^{17}$ Libraries are beginning to adopt this type of approach as a way of integrating technology staff with others such as outreach and public services staff, organizing staff around specific "products" or services for users. For example, one library has created a team focused on local digital collections that brings together developers working on the institutional repository and the staff that work programmatically on library digital collections. ${ }^{18}$

In a very few cases, libraries are adopting one of the "agile" software development methodologies, such as Scrum, as the organizing principle for these teams (and in some cases beyond). ${ }^{19}$ No library in this project's sample has deployed these methodologies in a broad and fully realized fashion. Still, these methodologies are directionally very innovative, and they are perhaps challenging to implement in a familiar research library environment. They push towards self-organization (through a non-traditional organizational structure that features individuals in enabler rather than managerial roles) managed through high level performance indicators (such as "Increase by $20 \%$ annually the share of the most recent year's publications from our own institution that are deposited in the repository" or "Increase by $60 \%$ the annual number of off-campus downloads from the repository"). Progress towards these indicators is realized through techniques such as an evolving series of feature backlogs, efforts to map capacity to priorities, daily stand-up meetings and visual representations of progress to bring complete transparency to team member contributions and needs, and short-term sprints of work that are completed with reviews for all in the organization to see and monitor progress.

\footnotetext{
${ }^{17}$ Marty Cagan, Moving from an IT to a Product Organization, July 6, 2008, http://www.svpg.com/moving-from-an-it-to-aproduct-organization/.

${ }^{18}$ These teams are intended to solve some of the organizational barriers that otherwise seem to exist. One user experience librarian has said that "the thing that everyone seems to be grappling with is how to integrate yourself into the organization and prove your worth and value. Academic libraries tend to be more hierarchical so there might be more issues there. For example I report to the head of public services and the web development team reports to the head of library ITS. In an ideal world we would work together," http://ux.prattsils.org/2015/10/public-services-2-0-the-future-of-uxin-libraries-an-interview-with-nadaleen-tempelman-kluit/.

${ }^{19}$ See for example https://www.scrumalliance.org/why-scrum.
} 
In such cases, these product teams are being integrated into functions such as public services, which are as a result being transformed. In one such case, while product orientation and agile methodologies are not yet fully realized, the director indicated the clear objective of building "an information organization," meaning an enterprise with information products and services, rather than any kind of incremental shift in the library. In cases where such a structure is realized in other enterprises, a manager takes responsibility for programmers and other systems staff, but does not serve as the executive for technology (i.e. CTO).

In other libraries, product teams are being created inside a standalone "innovation" part of the organization, rather than on a whole-library basis. In such a case, traditional library operations are maintained in parallel while another team is responsible for spearheading a variety of digital library services. This will typically result when the organization as a whole is not seen as prepared, at least at this point, to undertake a broad transformation, coupled with a recognition of the necessity of continuing to deliver basic library services at appropriate quality levels without interruption.

Having afforded so much attention to new approaches, it is important at this point to emphasize that in most libraries whose director participated in this project there has yet to be a widespread reorganization of technology functions. The omnibus approach to technology leadership remains quite common.

Many directors spoke in concrete terms about their approach to making a large-scale technology decision like the selection of an integrated library system or systems platform. Given the generational transition to cloud-based platforms taking place in recent years, many interviewees have had recent opportunities to establish the decisionmaking processes associated with such undertakings.

Several interviewees asserted directly that the choice of systems platform was not a strategic choice for their library but was rather a pragmatic one. One asserted that these systems only support collections, which was said to be a declining role, or that the management challenges for e-resources were simply less complex than has been the case for print materials.

Several directors made the point indirectly, stating that they were moving or had moved to OCLC's WorldShare or Ex Libris's Alma, not as a result of a sophisticated decisionmaking process, but because such a process could be sidestepped. In these cases, the ability to build on an existing agreement rather than select a vendor competitively was a key factor in decision-making. This offers indirect evidence, at least, that purchasing practices at many universities are real constraints; several directors were comfortable 
eliminating most of the selection process to ensure a good enough outcome rather than following a process looking for a great outcome but risking a poor one.

The shift to a new systems platform is strategic when it allows for new kinds of collaboration. When the library system supports multiple library organizations, such as a consortium or a university library as well as a law or medical library, the decisionmaking is seen as more strategic as it gets at the heart of the opportunities to collaborate. Directors generated this enthusiasm by the prospect of a cloud-based common systems environment that allowed deeper collaboration than would previously have been available. They will typically focus the collaborative decision-making process on which platform to choose, reserving for later a discussion of how best to take advantage of this new collaboration environment.

Directors typically expressed interest in selecting the discovery service offered by their systems platform vendor. They saw this as an opportunity to make a single decision that would aid integration over time. In other words, the same decision-making structures and process that selected the systems platform also tended as a by-product to select the discovery service.

\section{Undertaking a Restructuring: Approaches and Constraints}

Directors pointed to two different types of reorganization. One is designed to fix problems in a unit or division or to address some other immediate challenge. Interviewees emphasized the care that needs to be taken in assessing problems in the organization, especially when one is relatively new in one's position. Is it just finger pointing? Is there an individual or group of people that are creating problems? Is it the work design? Or is it in fact the structure? Addressing the wrong issues will not fix the underlying problem, so only sometimes should a problem drive a reorganization.

The second type of reorganization is more comprehensive and is designed to take advantage of a rare opportunity to rethink the way the parts of the library connect to one another. Such reorganizations often take place early in the tenure of a new leader or because of a confluence of departures in the leadership team.

Several long-standing directors, in some cases with experience across multiple libraries, spoke eloquently about how organizational structure and leadership roles are appropriate to a given period in an organization's development rather than of enduring value. For these directors, organizational structure is not something to try to perfect. Rather, it is contingent on the needs of the campus and the abilities of the library. Consequently, the best organizational structure for today will be imperfect and will at 
some point in the future need to be rethought, so a regular reexamination of structure and leadership roles is an important ongoing responsibility of the director.

\section{The best organizational structure for today will be imperfect and will at some point in the future need to be rethought.}

In principle, it may be the case that structure is reexamined not because problems exist or a rare opportunity develops but because the organization is striving constantly to realize its full potential. But in practice, large-scale reorganizations impose stress on employees and the organization as a whole and are sometimes avoided by leaders more than they are embraced.

Several directors spoke about the process they utilized in mounting a reorganization. Sometimes decisions about structure are delegated to a working group, with the director reviewing progress but maintaining a position of being open to a variety of structures. More typically the director maintains a firm hand. One director spoke about conducting a listening tour across the library and around the campus soon after being hired, using this as the basis for sharing a report on what had been heard and what they proposed doing. Sometimes an outside consultant is engaged to facilitate an organizational redesign process and issue one or several recommendations. One director indicated candidly that "The leadership had some ideas going on behind the scenes but we structured this as an inclusive process." When there is a proposal from the director that requires approval, explicitly or implicitly, there is often a great deal of capital placed on gaining that approval and a fear of consequences should that approval not be received.

\section{Reflections}

In examining the structures at nearly 20 research libraries, this project has found some important alliances between efforts to clarify strategic priorities and the organizational structures seen as needed to support these priorities. The best-developed example of this was in the areas of collections. There, where clear objectives have emerged to shift the pattern of spending to deliver unique value, a structure is being created at many research libraries to align responsibilities appropriately. Articulating strategic objectives across the library with a high level of clarity is vital. 


\section{Articulating strategic objectives across the library with a high level of clarity is vital.}

It is a mistake to see organizational structure as necessarily a hierarchical and bureaucratic topic. An important theme that recurred across interviews was the need to empower staff throughout the organization and bring focus to strategic priorities beyond operational responsibilities. Traditional shadow structures of committees and working groups were seen as increasingly ineffective. Several libraries are implementing new and more agile models that upset the hierarchical assumptions, often driven by library technology units but sometimes extending well beyond. In a number of libraries, shadow structures are being grafted into the formal hierarchy, or the hierarchy remade around the shadow structures. Organizational structures and cultures can evolve in research libraries just as much as they are evolving in other enterprises attempting to position themselves for greater agility in providing services that are reliant on technology.

\section{In a number of libraries, shadow structures are being grafted into the formal hierarchy.}

Of course, there are real challenges. Some impediments, such as inflexible work rules and aspects of organizational culture, are the reality for any library attempting to remake itself. Some directors expressed basic comfort with the impediments they have faced, while others were truly frustrated by them.

Another important challenge, observed at several of the participating libraries, was about how best to manage and lead technology functions. The ability to manage technologydependent public services at an executive level is clearly a growing requirement for library leaders.

Several of the directors reflected personally on struggles they have faced. The most problematic were cases where they accepted a position out of excitement for a new executive opportunity in a new organization-rather than with eyes wide open about the organization and its challenges.

The reality is that organizations and leaders alike are complex. Library leaders will benefit from examining organizational structure from an organization and management 
perspective, but in any given organization it is important to understand structure in the context of organizational culture and climate, power and leadership, shared governance, and other issues.

Even so, many research libraries are making important efforts to rethink organizational structure in ways that are no longer just experimental. As the library moves to become more integrated with institutional strategies in support of research excellence and student success, regular efforts to align the organization with its strategy and that of its parent university are the essential work of any research library leader today.

\section{Appendix A}

- What are the library's formal and informal organizational structures? How have they been changed over time and why? What works well and what could be improved?

- How is your strategic plan reflected in organizational structure and staffing?

- Walking through some of the following responsibilities, how is each situated within the library and how effective do you see your library's decision-making on each?

- Evaluating and selecting among options for library systems

- Streamlining discovery of and access to information resources

- Developing services to address changing research, teaching, \& learning practices

- Market research, analytics, and service quality assessment

- Collections development and preservation

- Digital collections

- And then a few questions on areas of specific change:

- How is library technology acquisitions and development organized? How do systems infrastructure and organizational structure relate to one another?

- What structures and systems have changed to accommodate strategic shifts such as away from print collections and towards user-centric services?

- How does the library's reporting relationship with its parent university affect these issues if at all? How do consortial or state system affiliations affect these issues if at all?

- If you were able to build your university's library from scratch today, how would you build it differently, in terms of organizational structure? What constraints have you faced in achieving this type of structure? 